\title{
PENSAR FOTOGRAFÍAS-SEDUCIR PALABRAS
}

Think photographs - seduce words

Anderson Hardy González Sapuy*

González, A.H. (2016). Pensar fotografías-seducir palabras. Revista PACA, 8, 157-170

\section{Resumen}

Como consecuencia de la indiferencia que muestran los estudiantes frente a los procesos de lectura/escritura, es necesario que los docentes adoptemos estrategias didáctico-pedagógicas para inducirles gusto, comprensión y asimilación de estos procesos intelectivos que construyen su aprendizaje.

Desde nuestra experiencia como docentes investigadores de procesos lectores/escritores en el aula escolar, pudimos determinar que vincular actividades de observación, reconocimiento y valoración de imágenes fotográficas que hacen parte de la cotidianidad de nuestros estudiantes ha ofrecido oportunidades ventajosas para propiciar los procesos académicos de aprendizaje. De esta manera surgió el proyecto Pensar fotografías-Seducir palabras, que tuvo como objetivo general determinar la incidencia del uso de fotografías documentales en el proceso lector de los estudiantes de los grados sexto, séptimo $A$, séptimo $B$ y octavo de la Institución Educativa Naranjal, del municipio de Timaná.

* Magister en Educación. Docente de la institución educativa María Auxiliadora del Municpio de Elías, Huila. Email: anderson050990@hotmail.com 
El enfoque mixto orientó el proceso investigativo, específicamente con el Diseño Explicativo Secuencial (DEXPLIS). Como estrategia investigativa cuantitativa, se utilizó una encuesta diagnóstica al iniciar el proceso y una encuesta al finalizar el mismo. Como estrategia investigativa cualitativa se utilizó el diario de campo y la observación participante.

Se compendiaron resultados de investigaciones que realizaron diversos estudiosos que utilizan la fotografía como elemento didáctico-pedagógico en el proceso educativo. Los fundamentos teóricos se ajustaron a conceptualizaciones relacionadas con la función didáctica de la imagen como potenciadora de significado y a teorías didáctico-pedagógicas que permiten ser articuladas en el entorno escolar con la imagen.

Palabras clave: Lectura, aprendizaje, fotografía, didáctica, estrategia pedagógica.

\section{Summary}

As a consequence of the indifferent of the students about the reading and writing processes, the teachers must adopt strategies (Didacticaspedagogicas) to make them appreciate this process for their learning.

From our experience as teacher investigators of reading and writing processes in the room class, we were able to determine that we linking activities of observation, recognition and appreciation of photographic images that are part of the daily lives of our students, has created advantage opportunities for the academic processes of learning, so that the project: "PENSAR FOTOGRAFÍAS - SEDUCIR PALABRAS" came up to determinate the use of documental photography in the student's reading processes of 6th and 7th A, 7th B degrees, and also 8th from the Naranjal Institution in Timaná - Huila.

This mixed focus oriented the investigation, to specifically the sequential explanatory design (DIMPLES). As a quantitative investigation strategy, we used a diagnostic inquiry to begin the process and another to finish the same one. As qualitative research strategy we used a field dairy and participant observation. 
It was compiled investigation results made by different people using the photographic as a didactic-pedagogic element into the education process, the theorical basis were according to concepts related to the (didactical) function of the image as enhancer of meaning and to didactic and pedagogical theories that allows being used in the school environment with the image.

Key words: Reading, learning, photography, didactic, pedagogical strategy

\section{Introducción}

Actualmente las generaciones humanas abren sus ojos a un contexto visual; por lo tanto, esta sociedad tecnológica exige niveles de competencia sobresalientes en la observación y el análisis de imágenes.

No obstante, a pesar de ser una actividad cotidiana y aunque parezca paradójico, en los planes de estudio de las instituciones educativas su influencia es decorativa y su aplicación pedagógica superficial. Los libros de textos, para ser más específicos y citar un ejemplo, tienen en su contenido gran cantidad de fotografías que funcionan como decoraciones de los textos y su nivel semiótico pasa a un plano secundario.

En efecto, hemos creado en nuestros estudiantes un concepto equivoco de lectura, limitado al proceso físico y cognitivo de deletrear símbolos; así hemos menoscabado la importancia de la imagen y su capacidad para abstraer y potenciar significados y conocimiento en el aula.

Cuando desde la edad escolar -incluso desde antes- se forma y contagia al niño con la necesidad de escudriñar las imágenes que hay a su alrededor, el docente hace que la creatividad y el pensamiento crítico hagan su aparición en cada escenario cotidiano, pues los mensajes en las imágenes van a ser cifrados y la emoción creadora siempre va a estar presente en su desciframiento.

Por medio de la imagen, el estudiante crea sus propios significados antes de entrar en contacto con referentes que contaminen su imaginación y conceptualización de la realidad.

Al trabajar el proceso lector/escritor con fotografías documentales de la 
región, los estudiantes recuperaron el sentido de la identidad en ocasiones perdido y, gracias a las imágenes escogidas y a la difusión del contenido de los talleres, no sólo se observó en el grupo de trabajo y en la Institución, sino en toda la comunidad.

Con esta investigación se procuró crear consciencia de la importancia de retomar nuestras raíces y nuestra historia, creando un puente con la academia. Los docentes observamos con frecuencia la incursión de programas y metodologías extemporáneas, que lejos de crear en los estudiantes el deseo incesante por aprender, logran efectos adversos. Cuando los estudiantes leían fotografías de antaño de su lugar de origen en la que se evidenciaban calles vacías que en la actualidad se encuentran pobladas, de sitios emblemáticos modificados por el manto casi ineludible de la modernidad y por el efecto devastador que ensaña el tiempo, de personajes que hicieron historia y que hoy mantienen algún rango de consanguinidad con los estudiantes participantes del taller, ocurrió que ellos se sintieran cada vez más motivados para participar dinámicamente en el proceso de lectura, lo que constituyó una herramienta epistemológica para hacer reflexionar a toda una Institución respecto al trabajo educativo necesario, en torno a rememorar el pasado como fuente primaria para una educación auténtica de los adolescentes, necesidad vital no sólo de un municipio, sino de toda nuestra Nación, gracias a la lectura.

A partir de los resultados obtenidos en la investigación se aportaron herramientas que permitieron fomentar de manera activa y lúdica el proceso lector/escritor.

\section{Marco teórico}

Con respecto a los estudios concernientes de los antecedentes investigativos, las propuestas de tres profesores de la Universidad Complutense de Madrid orientaron el proceso; son ellos, Juan Miguel Sánchez Vigil, doctor en Ciencias de la Información, fotógrafo, escritor de libros para niños y para adultos, documentalista gráfico en la editorial Espasa Calpe, quien ha merecido reconocimiento de su labor de escritor. Su tesis doctoral se intitula "Documentación Fotográfica en España"; María Olivera Zaldúa, doctorada en Ciencias de la Información; su tesis doctoral se denomina "La colección Iconográfica del compositor Joaquín Turina"; y 
Juan Carlos Marcos Recio, cuya tesis doctoral Cum Laude versó sobre las nuevas tecnologías de la documentación aplicadas a los medios de comunicación, especialmente a los periódicos electrónicos ${ }^{45}$.

Los profesores citados hicieron un banco de imágenes fotográficas de uso y aplicación educativos para estudiantes, docentes e investigadores en su proyecto educativo "Imaginando". El banco de imágenes fue elaborado por los mismos estudiantes, partían de un consenso de los objetos a fotografiar; posteriormente, analizaron las imágenes seleccionadas asociando imagen-concepto, para expresar ideas y contenidos icónicos significativos para los estudiantes y su entorno.

Durante este proceso, los profesores observaron que el uso de la fotografía en la docencia despertaba el interés en los alumnos, fomentaba su participación en el aula y fuera de ella, mejoraba la interacción entre los estudiantes y estimulaba el debate. Se percataron además de que se abría una vía de estudio con la relación imagen-texto, gracias a los pie de fotos que incluían en sus fichas de trabajo.

También se consultó la investigación de Daiana Rigo ${ }^{46}$, licenciada en Psicopedagogía, Magister en Psicología de la Educación e interesada por los temas académicos que se desenvuelven en el ámbito de la educación: inteligencia, creatividad, diseños curriculares, evaluación auténtica, motivación, tareas académicas. La profesora argentina presenta una experiencia didáctica en torno al uso de fotografías, imágenes y obras de arte en las aulas, y la percepción que tuvieron los estudiantes de grado sexto, del área de Ciencias sociales. De acuerdo con la información obtenida en las encuestas, en los resultados constató que más de tres cuartos de los alumnos entrevistados afirmaban que aprendieron con imágenes, porque les facilitó el contacto con el contenido y su comprensión, e hizo que los conceptos fueran más fáciles de recordar. La profesora Rigo señaló también que

(...) el uso de imágenes, fotografías y obras de arte resulta positivo

\footnotetext{
${ }^{45}$ Juan Miguel Sánchez Vigil, María Olivera Zaldua; Juan Carlos Marcos Recio. Modelos para el uso de la fotografía en la docencia: El proyecto Imaginando. // Ibersid. 8 (2014) 33-41. ISSN 1888-0967.

${ }^{46}$ D. Y. Rigo (2014). Aprender y enseñar a través de imágenes. Desafío educativo, ASRI: Arte y sociedad. Revista de investigación (6), p. 6.
} 
para los aprendizajes de los estudiantes, en el sentido de crear instancias de comprensión y de motivación. Asimismo, los resultados posibilitan responder a tres interrogatorios que surgen de los datos recolectados y en función de la valoración ofrecida por los alumnos:

1) ¿Qué funciones cumple la imagen en la tarea y en el aprendizaje? Al parecer la imagen como recurso didáctico posibilita activar los conocimientos previos, relacionar conceptos con la vida real, comprender temáticas, entablar una comunicación auténtica y retener lo aprendido; 2) ¿Cómo usar la imagen en enseñanza para promover la comprensión? Por un lado, se rescata la importancia de guiar la lectura de las imágenes a partir de preguntas centrales que estimulen la descripción, así como la formulación de inferencias, hipótesis y relaciones entre conceptos, por otro lado, se resalta la relevancia de complementar la lectura de imágenes con otro tipo de material de estudio; y 3) ¿Cómo el aprendiz percibe la tarea? Como potencialmente promotora de motivación y de nuevos aprendizajes. ${ }^{47}$

Para finalizar este apartado de antecedentes investigativos, se evidencia el trabajo de la colombiana Ángela Díaz ${ }^{48}$, Magister en Lingüística de la universidad Pedagógica y Tecnológica de Colombia, reconocida por publicaciones como "La imagen metafórica publicitaria, semiótica y cuerpo: Taichichuan, imagen y pedagogía"; que construye toda una teoría de la imagen y su influencia en el proceso educativo de los estudiantes.

Para realizar el proceso, la profesora Díaz tiene como eje vertebral los postulados de:

- Michael Presseley, historiador de arte y escritor británico.

- Roland Barthes, ensayista, crítico literario y semiólogo francés.

- Rudolf Arnheim, psicólogo y filósofo alemán.

- Platón, filósofo griego seguidor de Sócrates y maestro de Aristóteles.

- David Perkins, co-director del Harvard Project Zero y principal orador del III Seminario Internacional de Educación de calidad contra la Pobreza, en el año 2010.

- Perry Nodelman, profesor emérito de la Universidad de Winnipeg, Doctor en Literatura Victoriana de Yale y famoso por sus libros para niños.

\footnotetext{
${ }^{47}$ Ibíd., p. 8

${ }^{48}$ Ángela M. Díaz (2009). Imagen y pedagogía. Cuadernos de Lingüística Hispánica (13), p. 143-154
} 
- Jordi Pericot Canaleta, licenciado en Filosofía y doctor en Historia del Arte, director de la revista Temes de Disseny e investigador pedagógico en los ámbitos de la imagen.

- Joan Ferrés Prats, doctor en Ciencias de la Información, guionista y realizador de audiovisuales educativos, profesor en la Universidad de Pompeu Fabra en el área de Comunicación Audiovisual.

- Robyn Quin, profesora de Comunicación y jefa del Departamento de Lengua, Literatura y Medios de Comunicación en la Universidad de Edith Cowan (Australia Occidental).

- Martine Joly, profesor de la Universidad Michel de Montaigne -Bordeaux III-, participante en el desarrollo de múltiples estudios sobre la imagen.

Respecto al componente teórico de la investigación, el eje vertebral fueron los planteamientos del filósofo y psicólogo alemán Rudolf Arnheim, con sus modernos e innovadores planteamientos del arte visual como percepción sensible y cognitiva de la realidad. También, el teórico y crítico de cine Jacques Aumont, con sus postulados en torno a la imagen, centrados en temas como condiciones y procesos físicos para observación de imágenes, el papel del espectador en el proceso de observación, la función de la imagen y el papel de la imagen como arte. Además, los profesores Lorenzo Vilches, con sus connotaciones respecto a la imagen vista como un texto y al papel del lector en la interpretación de la misma, y Michael Presseley, docente de psicología de la universidad Notre Dame, con su amplio recorrido en temas investigativos que conciernen a la enseñanza de la lectura y su concepción de la escritura como respuesta a las imágenes; el aporte del historiador alemán Hans Belting, con su concepción antropológica de la imagen, y del pedagogo brasileño Paulo Freire, con su pedagogía dialógica, centrada en la observación de la realidad y en el estudiante.

\section{Metodología}

El diseño seleccionado para la presente investigación se desarrolló bajo los parámetros del enfoque mixto, específicamente Diseño Explicativo Secuencial (DEXPLIS). Como estrategia investigativa cuantitativa, la encuesta diagnóstica al iniciar el proceso y la encuesta de comprobación al finalizar el mismo. Como estrategia investigativa cualitativa, se utilizaron el diario de campo y la observación participante. 


\section{Muestra}

En la presente investigación la muestra fueron 60 estudiantes de los grados sexto, séptimo A, séptimo B y octavo, de la Institución Educativa Naranjal, escogidos de manera aleatoria.

Con respecto al porqué se escogieron estos grados para realizar la investigación cabe mencionar que, según los docentes orientadores de las áreas de lengua castellana, ética y valores y el Rector de la Institución, son los grados que presentan más dificultades disciplinarias y por ende, desde mi perspectiva, fue una oportunidad para hacer trabajo académico exitoso con estos estudiantes.

\section{Procedimientos}

El proceso investigativo se desarrolló en tres etapas secuenciales:

ETAPA I: Aplicación de la Encuesta número 1. La Encuesta sirvió para obtener una visión clara respecto a las intenciones que tenían los estudiantes frente a las fotografías, a la lectura y a un proceso lector con este tipo de material. A partir de los resultados obtenidos, se obtuvieron elementos importantes para la formulación de los talleres y para la escogencia de las fotografías que cubrieran las expectativas de los estudiantes. Después de haber aplicado el instrumento, se analizó la Encuesta a partir de la representación estadística con gráficos circulares, también llamados "tortas". El análisis de los gráficos estuvo mediado por el siguiente orden: mostrar, describir y explicar o concluir.

ETAPA II: Aplicación de los talleres de lectura de fotografías, siguiendo la secuencia:

- Observación de cortometraje hecho a partir de fotografías, y espacio para el diálogo.

- Observación de la fotografía y diligenciamiento de ficha número 1 para análisis de fotografía.

- Contextualización de la fotografía -autor real, título real, contexto real, y contraste entre las inferencias escritas en la ficha y las que escucharon en la contextualización-.

- Diligenciamiento de ficha número dos para análisis de fotografía. 
Se observaron tres fotografías por sesión de talleres, tres sesiones en total, los días sábados en la institución educativa mencionada. Las fotografías se proyectaron con Video Beam de alta resolución. En la última sesión de talleres no se aplicaron las fichas de lectura de fotografías de manera escrita, fue de forma oral y hubo espacio para las creaciones trazadas por los estudiantes, en las que manifestaron libremente su manera de ver y entender el proceso lector durante los talleres.

La información recogida a partir de las fichas sirvió para afianzar y alimentar el diario de campo, que fue un elemento vital para recoger resultados y conclusiones.

ETAPA III: Aplicación de la Encuesta número 2. Después de haber aplicado el instrumento, se analizó a partir de la representación estadística con gráficos circulares, también llamados "tortas". El análisis de los gráficos estuvo mediado por el siguiente orden: mostrar, describir y explicar o concluir.

En su forma, las dos encuestas tienen los siguientes parámetros: Objetivo, Metodología, Alcances y Limitaciones, Cuestionario, Resultados, Observaciones Planteadas.

\section{Conclusiones}

Teniendo como referencia el objetivo general, y por ende los objetivos específicos de la investigación, las conclusiones del proceso investigativo implican contribuciones teóricas y didáctico-pedagógicas y sugerencias para futuros estudios en torno al tema.

Con respecto a los referentes bibliográficos de los antecedentes investigativos, se logró hacer un rastreo a estudios que tenían como eje vertebral el manejo de la imagen en el proceso educativo y su influencia como material didáctico-pedagógico, para acotar parámetros al plantear trabajos de prácticas contextualizadas en el proceso lector de los estudiantes, con la fotografía como recurso comprensible.

Los trabajos tenidos en cuenta en las etapas ya descritas y los referentes teóricos esbozaron temas, estrategias y conceptualizaciones respecto al manejo de la imagen en la enseñanza escolar. Desde esta perspectiva, el estudio realizado permitió el fortalecimiento y crecimiento investigativos 
que repercuten en la línea de didáctica en la lengua castellana, en el proceso lecto-escritor.

Al realizar la encuesta diagnóstica en los estudiantes de los grados sexto, séptimo A, séptimo B y octavo de la Institución Educativa Naranjal se logró evidenciar que, aunque la mayoría de los estudiantes habían tenido contacto con fotografías en su vida cotidiana, este material no se había utilizado pedagógicamente en su proceso educativo en la escuela. En este sentido, la Encuesta fue fundamental porque arrojó intereses de los estudiantes frente al uso de dicho recurso y consolidó una fuente para formular los talleres de lectura de fotografías.

De otro lado, respecto a la búsqueda de fotografías en el centro poblado del municipio, fue una oportunidad para dar voz a los ancianos de la región, para que el relato de su vida misma fuese escuchado, que su vestigio de subsistencia por medio de fotografías tuviera palabra y que su testimonio histórico de cambios constantes en la región se pudiera convertir en el elemento perfecto para que la historia de un poblado (desconocido en ocasiones por sus mismos habitantes), pudiera ser reconocido, escuchado, leído.

Frente a la pregunta de investigación ¿Qué incidencia ejerce la utilización de fotografía documental en el proceso lector de los estudiantes de los grados sexto, séptimo A, séptimo $B$ y octavo de la Institución Educativa Naranjal, del municipio de Timaná?, se puede concluir que:

El trabajo de lectura con fotografías documentales de la región con los 60 estudiantes de la Institución mostró como resultado un proceso de lectura reflexivo y crítico. Las fotografías del contexto permitieron realizar actividades aterrizadas a sus necesidades; despertaron la emotividad, las asociaciones y el interés por conocer rasgos históricos de su lugar de origen.

A partir de los talleres, teniendo como eje vertebral las fichas de lectura, los estudiantes crearon bases personales para observar y leer imágenes, las inferencias hacían su aparición cada vez más elaboradas y los juicios de valor con cada fotografía eran mejor argumentados. 
Las fotografías permitieron hacer un proceso de lectura retrospectivo al pueblo; era común escuchar comentarios en las participaciones y en las fichas de análisis y lectura de fotografías que obedecían a costumbres perdidas en el lugar, así como a un desarrollo precario en muchos ámbitos del pueblo y cómo la modernidad llegaba a sus pobladores con pasos lentos y no constantes.

Al encontrar fotografías del templo, del colegio, de una de las fincas más importantes del poblado, del denominado "Tanque", que suplía las necesidades de agua ante los constantes veranos al no tener un acueducto, los estudiantes leían críticamente su situación como miembros de la comunidad. Conocer la historia del templo y saber que fueron mujeres quienes colocaron las primeras piedras de una majestuosa obra con estilo octogonal rotondo. Era común escuchar sus deseos de saber cuáles y en qué lugares sucedieron las actividades que realizaban sus abuelos, y la importancia cultural que tenían en su momento; observar las carencias en ausencia de un acueducto, los problemas del clientelismo, los favores y factores políticos.

Los colores en las fotografías permitieron leer con gran acercamiento la fecha de los hechos representados; fortalecieron y aportaron al crecimiento de principios identitarios, las maneras de vestir, los atuendos e incluso los gestos y emotividades presentes en las personas de la foto, permitieron hacer una lectura de clases sociales y distinción; reconocer en muchas de las personas de las fotografías a sus tatarabuelos, el lugar en el que está ubicada su casa cuando todo era hierba y árboles.

De esta manera, se pudo percibir e identificar por medio de las encuestas y talleres de lectura de fotografía sentimientos, percepciones, motivaciones y expectativas de los estudiantes frente a la lectura como práctica contextualizada. La emoción, la creación, la alegría, el interés era común encontrarlos reflejados en los rostros de los niños al observar y leer las fotos y en las respuestas otorgadas en las encuestas. He aquí la importancia que ejercen los sentimientos y su identificación en este trabajo investigativo. Sin duda, muchos de los planes lectores y de las estrategias para el fomento de la lectura no parten de llenar al niño y nutrirlo en su aspecto emocionalcognitivo, por tanto quedan solamente en la ensoñación. Es la diferencia de un trabajo que parte de la identificación emocional del estudiante frente 
al aprendizaje de la lectura y la escritura, y es hacia esa mirada que apunta su formación como persona crítica, dialógica y consciente de su tradición. Se observó que por medio de los talleres el interés por leer fue mayor, es aquí donde cobra importancia la metodología utilizada. Debido a que el modelo investigativo escogido permitió que los resultados cuantitativos arrojados en la primera encuesta fueran artífices para la construcción de la segunda etapa o etapa cualitativa y contrastar a su vez el proceso con una etapa cuantitativa comprobatoria final, contribuyó a que se pudiera demostrar la influencia de la fotografía documental en el proceso lector/ escritor.

De otra parte, cuando al estudiante se le atrapa desde la sensorialidad el interés cobra fuerza; al sensibilizar por medio de los olores, los estudiantes percibían un ambiente ajeno al que estaban acostumbrados y eso hacía que su atención y disposición mejoraran, la música escogida para los talleres fue vital, pues hacía parte de un lazo extraño y contemplativo entre fotografías, olor y música.

Las fichas de registro para lectura y análisis de fotografías fueron pertinentes, porque hacían que el estudiante fuera creador durante el proceso, y las preguntas estaban diseñadas para que inferencias, deducciones, comparaciones e hipótesis predictivas fueran una constante en el transcurso de la actividad, ya que estos elementos son indispensables para consolidar bases sobresalientes en el proceso lector de los estudiantes.

Sin embargo, vale la pena sugerir que para posibles estudios e implementación de las fichas para talleres de lectura, estas no se deben limitar solamente a diligenciarse de manera escrita, porque posibilitarán que el estudiante en el transcurso de los talleres sienta monotonía y el proceso no sea exitoso. Desde esta perspectiva, es conveniente que las fichas, en algunos talleres, sean diligenciadas de manera escrita, en otros, se socialicen de manera oral, en otros, se abra el espacio para la creación artística de los estudiantes.

Sin duda alguna, uno de los éxitos al implementar los talleres de lectura teniendo como eje vertebral las fotografías es la selección que el docente haga, según su contexto. En la medida en que las fotografías sean más contextualizadas, serán mucho más pertinentes y con base en la 
experiencia de este trabajo investigativo, los resultados serán más exitosos.

Por lo anterior, podría afirmarse tajantemente que la fotografía documental como estrategia didáctico-pedagógica sí incide en el proceso lector de los estudiantes de manera positiva, activando un sinnúmero de habilidades que tienen que ver directamente con el desarrollo del proceso lector.

Escribir, escuchar, hablar y leer son habilidades comunicativas que se entretejen y se enlazan de manera perfecta en los talleres de lectura de fotografías, la emotividad hace presencia de manera constante en las actividades y en la conformación de identidad hacia lo autóctono, formando de esta forma los lectores que, desde de mi perspectiva como investigador, necesita nuestro país: Arraigados a lo autóctono antes que a lo impuesto o importado, críticos frente a su contexto y que disfruten la lectura como una forma de vida y de vivir la vida.

\section{Rerefentes Bibliográficos}

- ARNHEIM, Rudolf (1997). Arte y percepción visual. Segunda edición. California: Alianza Forma, decimocuarta impresión.

- ARNHEIM, Rudolf (1986). El pensamiento visual. Primera edición. Barcelona: Paidós.

- AUMONT, J. (1992). La imagen. Barcelona: Paidós.

- DÍAZ, Á. M. (2009). Imagen y pedagogía. Cuadernos de Lingüística Hispánica, (13), 143-154.

- DICCIONARIO DE LA REAL ACADEMIA ESPAÑOLA \{En línea\}. Consultado diciembre 2014\} Disponible en:

- GADOTTI, Moacir. Paulo Freire, su vida y su obra. Primera edición: CODECAL http://buscon.rae.es/drae/srv/search?id=4k4Fsa7mdDXX20XX2B5r

- RIGO, D. Y. (2014). Aprender y enseñar a través de imágenes. Desafío educativo. ASRI: Arte y sociedad. Revista de investigación (6), p. 6.

- SÁNCHEZ Vigil, Juan Miguel; Olivera Zaldua, María; Marcos Recio, Juan Carlos (2014). Modelos para el uso de la fotografía en la docencia: El proyecto Imaginando. // Ibersid. 8, p. 33-41. ISSN 1888-0967.

- CONCEPTUALIZACIÓN TIPOS DE FOTOgRAFÍA \{En línea\}. Consultado diciembre 2014 Disponible en:

http://www.tiposde.org/general/482-tipos-de-fotografia/ 
Revista Paca No. 8

- CONCEPTUALIZACIÓN TIPOS DE FOTOGRAFÍA \{En línea\}. Consultado diciembre 2014. Disponible en:

http://es.wikipedia.org/wiki/Fotograf\%C3\%ADa_documental

- DEFINICIONES Y CARACTERIAZACIONES DE LA PALABRA IMAGEN \{En línea\}. Consultado febrero 2015 Disponible en:

http://glossarium.bitrum.unileon.es/Home/imagen 